\title{
On the path to 2025: understanding the Alzheimer's disease continuum
}

\author{
Paul S. Aisen ${ }^{1 *}$, Jeffrey Cummings ${ }^{2}$, Clifford R. Jack Jrr ${ }^{4}$ John C. Morris ${ }^{6}$, Reisa Sperling ${ }^{7}$, Lutz Frölich ${ }^{3}$, Roy W. Jones ${ }^{5}$,
} Sherie A. Dowsett ${ }^{8}$, Brandy R. Matthews ${ }^{8}$, Joel Raskin ${ }^{9}$, Philip Scheltens ${ }^{10}$ and Bruno Dubois ${ }^{11}$

\begin{abstract}
Basic research advances in recent years have furthered our understanding of the natural history of Alzheimer's disease (AD). It is now recognized that pathophysiological changes begin many years prior to clinical manifestations of disease and the spectrum of AD spans from clinically asymptomatic to severely impaired. Defining AD purely by its clinical presentation is thus artificial and efforts have been made to recognize the disease based on both clinical and biomarker findings. Advances with biomarkers have also prompted a shift in how the disease is considered as a clinico-pathophysiological entity, with an increasing appreciation that AD should not only be viewed with discrete and defined clinical stages, but as a multifaceted process moving along a seamless continuum. Acknowledging this concept is critical to understanding the development process for disease-modifying therapies, and for initiating effective diagnostic and disease management options. In this article, we discuss the concept of a disease continuum from pathophysiological, biomarker, and clinical perspectives, and highlight the importance of considering $A D$ as a continuum rather than discrete stages. While the pathophysiology of AD has still not been elucidated completely, there is ample evidence to support researchers and clinicians embracing the view of a disease continuum in their study, diagnosis, and management of the disease.
\end{abstract}

Keywords: Alzheimer's disease, Amyloid beta, Biomarker, Cognitive impairment, Clinical, Continuum, Dementia, Tau

\section{Background}

In the century since Alois Alzheimer discovered Alzheimer's disease (AD), scientists have made remarkable strides in understanding the illness [1], although it was not until the 1980s that two key molecular culprits in disease pathophysiology, amyloid beta $(A \beta)$ and tau proteins, were identified $[2,3]$.

Historically, the clinical definition of AD was considered probable because it was based on the systematic exclusion of other potential etiologies in a patient with a dementia syndrome and not on positive proof of $\mathrm{AD}$ pathology. Thus, AD could be confirmed only through postmortem findings or, rarely, in life by brain biopsy. Later, AD was defined in a broader sense based on clinical manifestations. With basic research advances in recent years, it is now recognized that, like many chronic diseases, pathophysiological changes begin many years prior to clinical manifestations of disease such that the

\footnotetext{
* Correspondence: paisen@usc.edu

'University of Southern California, San Diego, CA, USA

Full list of author information is available at the end of the article
}

spectrum of $\mathrm{AD}$ spans from clinically asymptomatic to severely impaired. As a result, defining $A D$ purely by its clinical presentation is artificial and efforts have been made to recognize the disease based on both clinical and biomarker findings.

Advances with biomarkers have prompted a shift in how the disease is considered as a clinicopathophysiological entity, with an increasing appreciation that AD should not be viewed with discrete and defined clinical stages, but as a multifaceted process moving along a continuum. Appreciating this concept is critical to understanding the distinction between $\mathrm{AD}$ and $\mathrm{AD}$ dementia, in order to initiate effective diagnostic and disease management options and for the development of effective disease-modifying therapies (DMTs).

The aim of this article is to discuss how our understanding of AD pathophysiology and the currently available biomarkers and clinical tools can assist with creating a more uniform approach (in both research and clinical practice) to conceptualizing $\mathrm{AD}$ as a continuum. This will help set the stage for the future management 
of $\mathrm{AD}$ and help lay a foundation for the prevention or effective treatment of AD by 2025, the year set by global leaders as the target for finding an effective way to treat or prevent $\mathrm{AD}[4]$.

\section{Understanding the disease continuum}

Based on currently available information, AD is best conceptualized as a biological and clinical continuum covering both the preclinical (clinically asymptomatic individuals with evidence of $\mathrm{AD}$ pathology) and clinical (symptomatic) phases of $\mathrm{AD}$. In the broadest sense, a continuum is defined as a seamless sequence in which adjacent elements (severities) are not perceptibly different from each other, although the extremes are distinct. In $\mathrm{AD}$, this equates to disease progression from an asymptomatic phase, through a long preclinical period during which pathophysiological changes are reflected by increasing biomarker evidence of disease, to the symptomatic phase, during which biomarker changes continue and symptoms of cognitive and then functional impairment become increasingly evident, with the eventual loss of independence and death. These changes in the individual components of the continuum occur in a sequential but overlapping manner.

\section{Disease etiology and pathophysiology}

The etiology of $\mathrm{AD}$ is complex and much remains to be fully elucidated. The close link between genetic mutations and disorders associated with $\mathrm{AD}$ (mutations of presenilin 1 (PS1), presenilin 2 (PS2), amyloid beta precursor protein (APP), and Trisomy 21) and the accumulation of $A \beta$ strongly implicates this molecule as a pathological driver in $\mathrm{AD}$, but there is controversy over whether $A \beta$ accumulation alone indicates inevitable progression to $\mathrm{AD}$. Furthermore, evidence indicates that $\mathrm{A} \beta$ accumulation alone is probably insufficient to produce symptoms [5-7]. At some point during the disease course, additional factors are involved in determining regional neurodegeneration [8]. Tau pathology has been suggested as a facilitator of the downstream effects of amyloid [9]. Other investigators have proposed that synaptic, mitochondrial, metabolic, inflammatory, neuronal, cytoskeletal, myelin, and other age-related alterations may also play a role in the pathogenesis of AD [10].

Based on our current understanding, histopathological characteristics of $\mathrm{AD}$ include 1) accumulation of amyloid plaques-extracellular deposition of $A \beta$ protein, both diffuse plaques of amorphous, primarily nonfibrillar $A \beta$ aggregates and neuritic plaques of fibrillar $A \beta$ arranged in a $\beta$-pleated conformation; 2) formation of neurofibrillary tangles (NFTs) - intraneuronal bundles of aggregated tau protein, including hyperphosphorylated tau (p-tau), forming paired helical filaments that aggregate within the neurons to create NFTs, leading to disruption of microtubule function, impaired axonal transport, and synaptic and neuronal injury; and 3) neurodegeneration-progressive loss of neurons or their processes (axons and dendrites) with a corresponding progressive impairment in neuronal function and loss of neurons and synapses (atrophy) [11]. Of note, these features individually are not diagnostic of AD. Several lines of evidence currently suggest that in $A D$ the interplay between $A \beta$ and tau is such that $A \beta$ can drive tau pathology and tau pathology may drive $A \beta$ pathology [12, 13]. Our understanding of the pathophysiology of $\mathrm{AD}$ is further complicated by primary age-related tauopathy (PART) $[14,15]$, a neuropathological condition revealed by tau imaging. PART is characterized by medial-temporal neurofibrillary pathology; the pathology remains localized and there are few or no $A \beta$ deposits.

The transition between healthy aging and preclinical $\mathrm{AD}$ is not well defined, at least with our current understanding. This shift is likely subtle and without discernible steps; one can suppose that a combination of genetic and environmental factors plays a role in the process [16]. Genetic factors that may contribute as disease modifiers include the apolipoprotein protein E epsilon 4 (APOE4) allele, which conveys an increased risk of disease, and more rapid cognitive decline in the setting of early AD pathology [17]. Other factors that may play a role include cardiovascular risk factors and lifestyle factors such as diet, physical exercise, and cognitive engagement. These lifestyle characteristics influence "cognitive reserve" and onset of objective cognitive decline [18]. The concept of brain or cognitive reserve was originally invoked to provide an explanation for the observation that the extent of AD histopathological changes at autopsy did not always align with the degree of clinical impairment. "Brain reserve" refers to the capacity of the brain to withstand pathological insult, perhaps because of greater synaptic density or a larger number of healthy neurons, such that sufficient neural substrate remains to support normal function. "Cognitive reserve" is thought to represent the ability to engage alternate brain networks or cognitive strategies to cope with the effects of encroaching pathology. While cognitive reserve may help delay the onset of clinical symptoms, once symptoms do emerge the rate of impairment may be greater [18] (i.e., there is a steeper trajectory for clinical impairment) because, while clinical symptoms are delayed, pathological changes progress.

The challenges in elucidating when pathophysiological changes start in the brain make it difficult to define a time of disease onset. Findings from epidemiologic studies suggest that midlife or earlier exposures (e.g., hypertension, smoking, diabetes, and 
obesity) increase the risk for subsequent clinically diagnosed AD dementia [19-21]. Available data are largely cross-sectional, although long-term population studies also provide evidence to suggest that late-life dementia may be linked to exposures occurring in early and midlife; these studies have not focused on AD specifically, and biomarkers were not considered. Recently initiated prospective cohort studies such as the PREVENT Project [22] will yield important information on the interplay between risk factors, biological and clinical changes, and the sequence of disease processes. Based on what we know today about $\mathrm{AD}$ pathophysiology and the sensitivity of currently available biomarkers, the starting point of disease is generally defined as when there is specific biomarker evidence of disease, more specifically the demonstration of $A \beta$ accumulation, as revealed by positron emission tomography (PET) or cerebrospinal fluid (CSF) analysis (Table 1).

\section{Biomarker and clinical findings along the continuum}

The AD continuum is composed of multiple interconnected components (pathophysiological processes, biomarker findings, and clinical symptoms), each occurring on its own trajectory, with individual trajectories generally parallel to each other but with some temporal offsets. The trajectories are influenced by modulating factors and, for both biomarkers and clinical symptoms, are dependent upon the sensitivity of the measurement.

\section{The preclinical phase of $A D$}

Exploring the continuum through the preclinical phase requires the use of biomarkers because

Table 1 Biomarkers currently in use in the AD field

\begin{tabular}{|c|c|}
\hline Biomarker & $\begin{array}{l}\text { Findings in } A D \\
\text { - other relevant notes }\end{array}$ \\
\hline \multicolumn{2}{|l|}{ CSF analysis } \\
\hline$A \beta_{1-42}$ & $\begin{array}{l}\text { Reduced concentration } \\
\text { - Measures soluble forms of } A \beta \\
\text { - Result of equilibrium shifts due to deposition/aggregation of } A \beta_{1-42} \text { in brain parenchyma or decreased } \\
\text { production of } A \beta_{1-42} \\
\text { - Level inversely reflects brain } A \beta \text { burden }\end{array}$ \\
\hline t-tau, p-tau & $\begin{array}{l}\text { Increased concentrations } \\
\text { - t-tau reflects the intensity of neuronal degeneration; it is elevated in other conditions such as head trauma, } \\
\text { CJD, and stroke and therefore not specific for AD } \\
\text { - p-tau is a marker of the abnormal pathophysiology associated with neurofibrillary tangle pathology } \\
\text { (hyperphosphorylation) in the brain. It is fairly specific for AD and is not elevated in primary tauopathies, } \\
\text { head injury, or stroke }\end{array}$ \\
\hline \multicolumn{2}{|l|}{ PET scan ${ }^{a}$} \\
\hline Amyloid PET & $\begin{array}{l}\text { Retention of amyloid tracer } \\
\text { - Amyloid tracers include }{ }^{11} \mathrm{C}-\mathrm{PiB} \text {, florbetapir (AV-45), } 91 \text { flutemetamol }\left({ }^{18} \mathrm{~F}-\mathrm{PiB} \text { derivative), florbetaben }(\mathrm{AV}-1) \text {, }\right. \\
\text { and AZD4694 } \\
\text { - Identifies fibrillar } \mathrm{A} \beta \text { and provides information about extent of } A \beta \text { plaque burden in brain }\end{array}$ \\
\hline FDG PET & $\begin{array}{l}\text { Evidence of reduced temporo-parietal glucose metabolism } \\
\text { - Flurodeoxyglucose }\left({ }^{18} \mathrm{~F}\right) \text { tracer } \\
\text { - Sensitive marker of synaptic dysfunction }\end{array}$ \\
\hline Tau PET & $\begin{array}{l}\text { Retention of tau tracer } \\
\text { - Tau tracers include flortaucipir (18 F-AV1451). Others are in development }\end{array}$ \\
\hline \multicolumn{2}{|l|}{ MRI } \\
\hline $\mathrm{fMRI}$ & $\begin{array}{l}\text { Measure of function } \\
\text { - Detects differences in BOLD signals over time and space } \\
\text { - Task-associated/based fMRI measures spatio-temporal changes in BOLD signal associated with administration } \\
\text { of a task during the scan } \\
\text { - Resting state fMRI measures spatio-temporal correlations in intrinsic or spontaneous fluctuation of BOLD signal } \\
\text { - Used to study functional networks (e.g., the default mode network) }\end{array}$ \\
\hline VMRI & $\begin{array}{l}\text { Volume or cortical thickness reduced } \\
\text { - Provides a measure of volume of whole brain, specific anatomical regions, or cortical thickness } \\
\text { - Demonstrates medial temporal atrophy and, more specifically, hippocampal atrophy; hippocampal volume is } \\
\text { reduced in many conditions, including old age, and several neurodegenerative disorders as well as } \\
\text { nonneurodegenerative disorders (e.g., diabetes, sleep apnea, bipolar disorder) }\end{array}$ \\
\hline
\end{tabular}

$A \beta$ amyloid beta, $A D$ Alzheimer's disease, CSF cerebrospinal fluid, $t$-tau total tau, $p$-tau phosphorylated tau, FDG flurodeoxyglucose, PiB Pittsburgh compound $\mathrm{B}$, $P E T$ positron emission tomography, MRI magnetic resonance imaging, $F M R I$ functional MRI, vMRI volumentric MRI, $B O L D$ blood oxygen level dependent, CJD Creutzfeldt-Jakob disease

a Uses specific ligands to detect AD pathophysiology in the brain 
individuals are apparently clinically normal. A number of diagnostic and progression markers have been described (Table 1), with the distinction being that diagnostic biomarkers are direct surrogates of brain AD lesions (amyloidosis or tauopathy) and therefore indicative of the presence of the disease, irrespective of stage, while progression markers identify downstream changes (metabolic changes, neuronal loss with atrophy) indicative of disease progression but not necessarily specific to AD [23]. Biomarker trajectories paralleling the hypothetical pathophysiological sequence of $\mathrm{AD}$ and specific biomarker changes over time were described by Jack et al. [24, 25] (Fig. 1).
The model presents the temporal evolution of five well-established $\mathrm{AD}$ biomarkers that provide a measure of brain $A \beta$ deposition, tau, or neurodegeneration both in relation to each other and to the onset and progression of clinical symptoms. The model assumes that each biomarker follows a nonlinear temporal course, which is hypothesized to be sigmoid shaped, and that the maximum rate of change moves sequentially from one biomarker to the next. While there is some individual variation, changes in markers of $\mathrm{A} \beta$ deposition generally precede those of tau and neurodegeneration. The model not only describes biomarker trajectories in the preclinical phase, but also in the clinical phase, when symptoms become evident. Support for this hypothetical model has

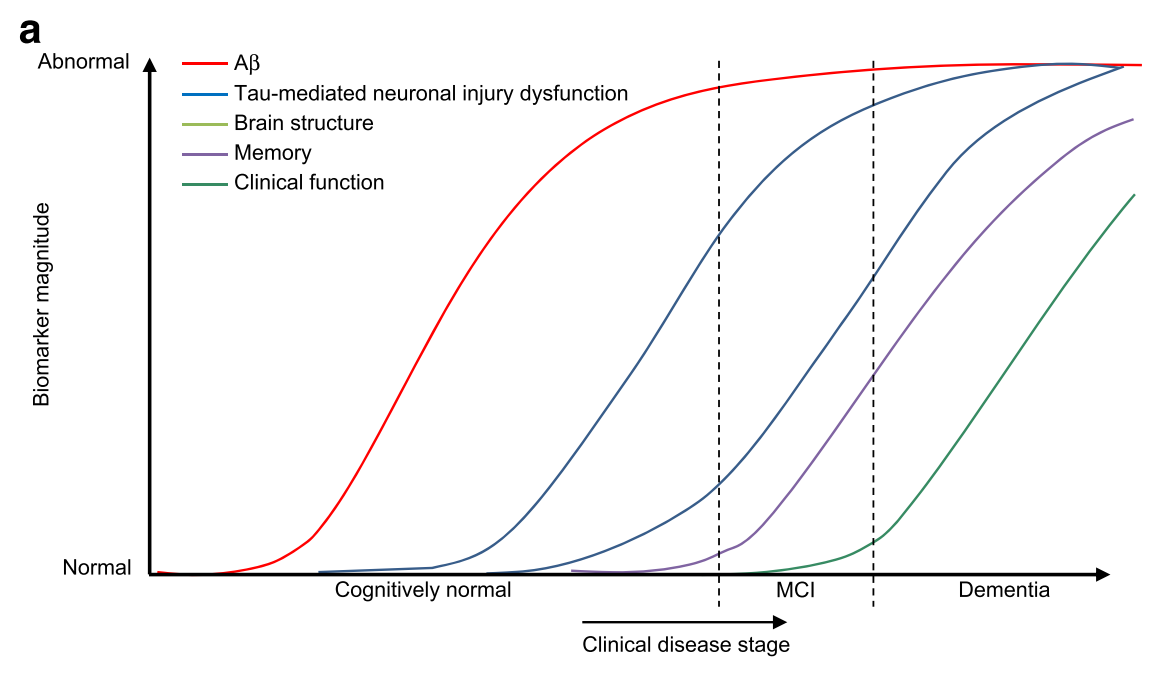

b

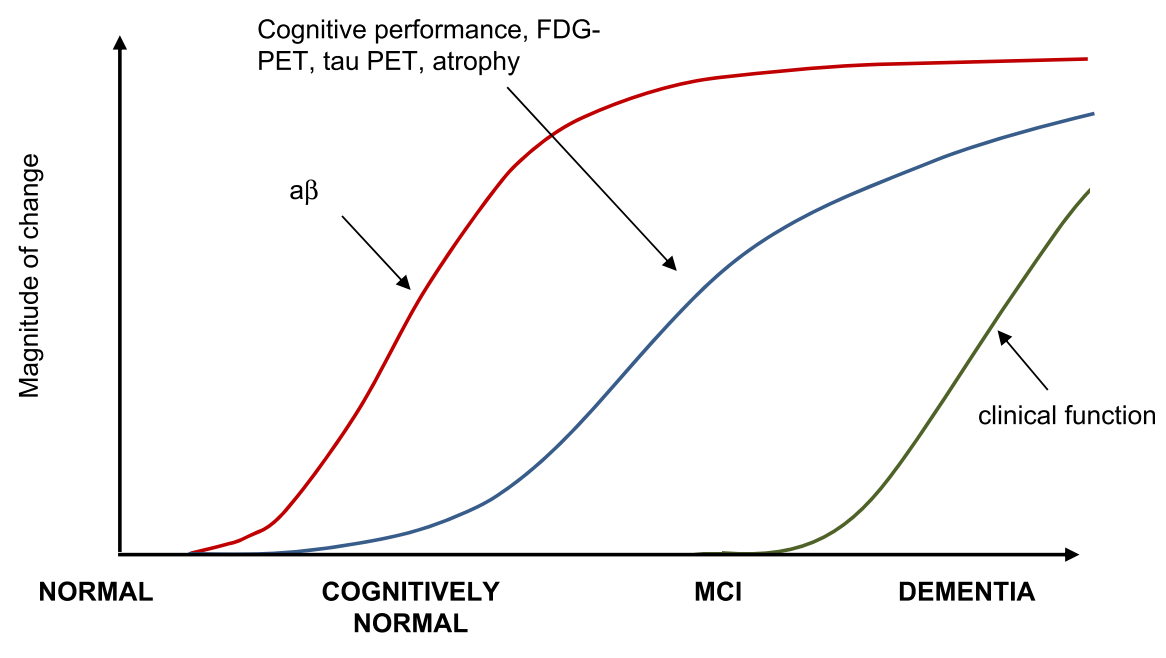

Clinical stage of disease

Fig. 1 Change in biomarkers over time. a Sequential change in measures of AD. Reproduced with permission from [24]. b Modified graph showing that amyloid accumulation (measured as low CSF A $\beta$ or elevated amyloid PET standard uptake value ratio) occurs first and functional decline occurs late in the continuum of AD (as before), but cognitive performance, FDG-PET, tau PET, and MRI atrophy change along a common, gradually steepening curve. $A \beta$ amyloid beta, FDG flurodeoxyglucose, PET positron emission tomography, $M C l$ mild cognitive impairment due to Alzheimer's disease 
been provided by cross-sectional biomarker data across the preclinical/clinical continuum [26-28].

\section{The transition to the clinical phase of AD}

Whether there is a specific threshold or regional distribution of $\mathrm{AD}$ pathology and/or a specific combination of biomarker abnormalities that will best predict the emergence of clinical symptoms remains unclear. Cognitive decline will likely occur only where there is $A \beta$ accumulation plus other changes-synaptic dysfunction and/or paired helical filament tangle formation, neurodegeneration, and neuronal loss $[29,30]$.

The time between $A \beta$ accumulation and clinical symptoms remains to be quantified, but current theories suggest that the onset of cognitive decline lags by at least 15 years [26, 31-33]. There are interindividual differences and some older individuals with preclinical evidence of pathophysiological changes may not become symptomatic during their lifetime, potentially the result of a more slowly progressing disease or death due to a competitive mortality. These interindividual differences are attributable to both environmental and genetic factors, including brain reserve, cognitive reserve, and genetic polymorphisms, as well as coexisting pathologies (age-related brain diseases) and medical comorbidities. As an example of the role of genetic factors, one allele of APOE4 shifts the risk curve for the disease to 5 years earlier, two copies of APOE4 shift it 10 years earlier, and one copy of the APOE2 allele shifts it 5 years later [34, 35].

The distinction between preclinical (asymptomatic) and early clinical (symptomatic) disease is subtle, and clinical manifestations of $\mathrm{AD}$ do not become apparent abruptly. Individuals with preclinical AD exhibit longitudinal decline on cognitive assessments even in the absence of clinically significant symptoms $[17,36]$. Some individuals are aware of subtle changes in cognitive function before they are detectable using currently available measures of episodic memory, psychomotor speed, verbal fluency, and concept formation [37-39].

\section{Advancing along the clinical continuum}

The clinical continuum includes trajectories for both cognition and function, each of which could be divided into further individual trajectories-for example, cognition includes trajectories of episodic memory, executive function, and verbal fluency; and function includes trajectories of both basic and complex activities of daily living (ADLs). Based on our current ability to detect deficits, cognition and function appear to decline on temporally offset trajectories and cognitive impairment precedes and predicts functional impairment [40].

While the concept of a continuum is biologically more appropriate for characterization of the course of $\mathrm{AD}$, some degree of staging has been helpful for clinical purposes; for example, assessing public health impact, clinical research purposes (trial population selection), standardized patient assessment and management in clinical practice, and health service utilization studies. Traditionally, the two key clinical stages have been considered mild cognitive impairment $(\mathrm{MCI})$ due to $\mathrm{AD}$, or prodromal $\mathrm{AD}$, and $\mathrm{AD}$ dementia, with dementia further divided into mild, moderate, and severe [41-43]. However, terminology such as "mild AD" and "moderate AD" is inaccurate-by the time an individual has mild or moderate dementia, they are far along the continuum and the disease has been present for many years, highlighting the important distinction between the syndromic and neuropathological diagnoses. In addition, while clinical staging nomenclature infers a clear distinction between the various stages, in reality the process progresses in a more continuous manner.

Whether or not one embraces clinical staging and the distinction between MCI and dementia, what is clear is that advancing along the clinical continuum there is progressive impairment of cognitive abilities and function. Cognitive deficits are often first apparent in episodic memory, and there is a specific profile of memory deficits, the amnestic syndrome, of "hippocampal type" [23, 43], characterized by diminished free and cued recall ability. This profile has been shown to be highly predictive for the presence of $\mathrm{AD}$ pathology [44]. Episodic memory loss is followed by or accompanies executive dysfunction (e.g., impaired planning and anticipation or failures on tests such as dual tasking and response inhibition), and language and recognition difficulties. Functional impairment is usually first apparent as subtle deficits in complex ADLs, such as problems with medication intake, telephone use, financial decisions, keeping appointments, and using everyday technology [45]. Impairment in basic ADL function (such as eating, dressing, and toileting) is generally not apparent until further along the clinical continuum. In a recurring theme, there are individual differences in rate of cognitive and functional decline, and not all individuals will progress to $\mathrm{AD}$ dementia or through the various $\mathrm{AD}$ dementia severities during their lifetime.

\section{Clinical implications of the continuum}

For the clinician, applying the continuum concept of $\mathrm{AD}$ raises several points of importance for counseling and prognostic discussions. $\mathrm{AD}$ can be diagnosed without dementia; an understanding of the biomarker changes is equally important to understanding clinical manifestations; and an appreciation for the temporal course of $\mathrm{AD}$ from preclinical biomarker evidence of disease through the presence of clinical symptoms is critical for effective disease diagnosis and management.

As 2025 approaches, there are other considerations concerning the continuum concept. There is currently 
no cure available but if forthcoming new treatments include DMTs that may have more impact if initiated earlier in the disease process, then earlier detection of disease is necessary. For more effective disease management, we also need to predict the future clinical course of disease more accurately. To achieve these goals, more research is needed to define biomarker profiles that best predict progression from the preclinical to the clinical stage and biomarker and/or cognitive profiles that best predict progression and rate of progression along the clinical course.

\section{Role of biomarker assessment}

While we know that pathological changes begin long before symptoms appear, determining whether biomarker evidence of pathophysiological changes in the preclinical stage implies definite progression to clinical disease during an individual's lifetime is difficult. Individual biomarkers do not provide definitive prognostic information. Recently, there have been efforts to improve diagnostic accuracy and ability to predict those at risk for clinical symptoms by considering a combination of biomarker findings. Jack et al. [46] proposed that diagnosis should be based on both the presence and absence of seven biomarkers in three categories (amyloid, tau, and neurodegeneration $(\mathrm{A} / \mathrm{T} / \mathrm{N}))$. Dubois et al. [47] proposed that diagnosis be based on both $A \beta$ and tau pathology. Using these criteria, the authors went further to differentiate between a "state" and a "stage". In simple terms, a state is considered asymptomatic at risk of $\mathrm{AD}$ (cognitively normal and amyloid or tau positive but not both) or AD (amyloid and tau positive), while a stage refers to the degree of disease progression within a given state (e.g., clinical $\mathrm{AD}$, preclinical $\mathrm{AD}, \mathrm{MCI}$ due to $\mathrm{AD}$ or prodromal $\mathrm{AD}$, dementia due to $\mathrm{AD}$ ). Conceptualizing $\mathrm{AD}$ as a continuum may favor describing the state as dichotomous and the stage as continuous.

Only a few years ago, diagnosis supported by biomarker findings (Table 1) was considered appropriate only for research-related purposes [41]; however, there is increasing effort to integrate biomarkers into clinical decision-making, with several PET tracers having received regulatory approval and CSF markers being measured with higher precision using advanced automated systems. CSF $A \beta_{42}$, total tau (t-tau), and phosphorylated tau (p-tau) biomarkers and amyloid PET have been the most widely studied $[48,49]$. More recently, tau PET has shown promise as a fairly specific marker of tau deposits characteristic of $\mathrm{AD}[30,50]$.

Biomarkers are now a key component of AD clinical trials, playing a central role in selecting individuals for whom the study treatment is most likely to be effective and providing objective evidence of target engagement and disease-modifying effects. Integration of biomarker assessment into more widespread clinical use would help with earlier and more accurate diagnosis. For example, approximately $25 \%$ of individuals referred for clinical trial participation with a clinical diagnosis of mild $\mathrm{AD}$ dementia have been shown to be $A \beta$-negative [51], an observation inconsistent with the clinico-biological concept of $\mathrm{AD}$, and this may be even higher in MCI due to $\mathrm{AD}$ [52]. Biomarker assessment would also assist with creation of uniform disease staging criteria for use in clinical research and practice, to enhance communication between research and practice, and help with transition of $\mathrm{AD}$ treatments from research to regulatory review to clinical practice. However, the clinical care environment has not yet evolved adequately for this to occur. In part, this is due to challenges with cost, standardization, accessibility, and incorporation of biomarker findings into patient treatment plans, but also, as mentioned previously, currently available biomarkers have limited ability to predict the clinical disease course. For clinical practice, we need simpler, less invasive, and more affordable biomarkers, as well as biomarkers that relate to other aspects of the disease.

\section{Role of clinical assessment}

Clinical assessment still provides the central approach to patient evaluation and should incorporate history taking from both patients and knowledgeable informants, supplemented by the use of cognitive and functional assessment tools. For detection of $\mathrm{AD}$ in the primary care setting, brief cognitive screening tools with adequate sensitivity may be helpful, although careful history taking from the individual and the family is essential. Tools that may be considered include questionnaires that probe for early change (e.g., Eight-item Interview to Differentiate Aging and Dementia (AD8), Cognitive Function Instrument (CFI)), brief global cognitive screens (e.g., MMSE), and more specific tests of episodic memory impairment indicative of hippocampal dysfunction (five-word test) (Table 2). For formal diagnosis in specialist practice, a more detailed clinical assessment, including neuropsychological testing, may be considered. Table 2 provides examples of other tools and their use within the $\mathrm{AD}$ continuum. While attributes of a specific tool dictate where it will be most useful, there is no consensus as to which tool is most appropriate for a specific clinical environment or time point along the continuum. In the future, we will certainly see computerized testing reaching clinical practice as well as the general population at large. While batteries will provide standardized and more rapid testing, they have not yet been developed sufficiently to be adopted widely.

In recent years, the focus in tool development has been on more sensitive cognitive measures that are able to detect subtle cognitive and functional impairment, to 
Table 2 Examples of clinical tools used and when in the disease course they are most useful

\begin{tabular}{|c|c|c|c|}
\hline & \multicolumn{3}{|l|}{ Examples of tools } \\
\hline & Brief tools for general setting & Neuropsychological testing & Clinical trials \\
\hline \multirow[t]{2}{*}{ Clinically normal/SCl } & CFI [55] & & ADCS-PACC ${ }^{a}[38]$ \\
\hline & & & $\mathrm{FCl}[56]$ \\
\hline \multirow[t]{9}{*}{$\mathrm{MCl}$ due to $\mathrm{AD} /$ prodromal $\mathrm{AD}$} & MIS [57] & FCSRT [58] & FCSRT [58] \\
\hline & AD8 [59] & RBANS [63] & $\mathrm{ADCOM}^{\mathrm{a}}[60]$ \\
\hline & GPCOG [61] & CVLT [66] & $\mathrm{FCl}[56]$ \\
\hline & Mini-cog [62] & & RBANS [63] \\
\hline & Five-word test $[64,65]$ & & \\
\hline & CFI [55] & & \\
\hline & MoCA [67] & & \\
\hline & ACE III [68] & & \\
\hline & MMSE [69] & & \\
\hline \multirow[t]{5}{*}{ Dementia } & MMSE [69] & ADAS-Cog [70] & ADAS-Cog [70] \\
\hline & ACE III [68] & RBANS [63] & CDR [71] \\
\hline & & & RBANS [63] \\
\hline & & & ADCS-ADL [53] \\
\hline & SIB [72] & & SIB [72] \\
\hline
\end{tabular}

a Composite tools-comprised of select items from existing scales

ACE III Addenbrooke's Cognitive Examination-III, AD Alzheimer's disease, AD8 Eight-item Informant Interview to Differentiate Aging and Dementia, ADAS-Cog Alzheimer's Disease Assessment Scale-cognitive subscale, $A D C O M$ AD composite, $A D C S$ Alzheimer's Disease Cooperative Study, ADL activities of daily living, CDR Clinical Dementia Rating, CFI Cognitive Function Instrument, CVLT California Verbal Learning Test, FCl Financial Capacity Instrument, FCSRT Free and Cued Selective Reminding Test, GPCOG General Practitioner Assessment of Cognition, MCI mild cognitive impairment, MIS Memory Impairment Screen, MMSE Mini-Mental State Examination, MoCA Montreal Cognitive Assessment, PACC Preclinical Alzheimer Cognitive Composite, RBANS Repeatable Battery for the Assessment of Neuropsychological Status, SIB Severe Impairment Battery, SCl subjective clinical impairment

lower the threshold at which clinical disease can be detected as well as to detect smaller changes in cognition/ function, to monitor disease progression along the continuum or therapeutic responses to interventions more accurately. Computerized tests that can be readily applied as screening tools in the primary care setting are also being introduced.

One key purpose of clinical assessment is to be able to predict the temporal path of $\mathrm{AD}$ at the individual level; for example, if and when $\mathrm{MCI}$ due to $\mathrm{AD}$ or prodromal $\mathrm{AD}$ will progress to $\mathrm{AD}$ dementia. Impairment in episodic memory (i.e., the ability to learn and retain new information) is seen most commonly in individuals who subsequently progress to a diagnosis of $\mathrm{AD}$ dementia $[42,54]$. Based on this, tools that assess episodic memory, both immediate and delayed recall, are valuable. Decline in executive functions may also flag incident $\mathrm{AD}$ dementia; by contrast, change in information processing speed/attention seems less informative [54].

\section{The future of AD management}

In the development of therapeutic interventions, there has generally been a shift in focus from $\mathrm{AD}$ dementia to $\mathrm{MCI}$ due to $\mathrm{AD} /$ prodromal $\mathrm{AD}$ and earlier; there is a need for a parallel shift in the diagnostic domain, beyond the research environment, to encourage lifestyle modifications and participation in clinical trials. An appreciation of the disease continuum engenders an awareness of our need to consider both diagnosis and therapies in a similar manner, along a continuum. That is, an individual treatment or management option may be most appropriate at a defined stage along the continuum, but its use will likely extend beyond this stage, and there will be overlap among the various treatment and management options such that more than one may be appropriate at any point on the continuum. This will be particularly relevant as new DMTs with different mechanisms of action become available.

With DMTs, treatment earlier in the disease continuum will likely be required to achieve more disease modification and maximize the opportunity of having an effect through slowing decline. If and when DMTs are approved for use, biomarker testing is likely to be central for early and more accurate diagnosis as well as for monitoring treatment effect. We can envision that biomarker findings will influence both initiation and termination of a specific treatment and may help determine whether combination therapies are appropriate and effective at the individual patient level. In particular, amyloid biomarkers will likely be necessary to identify candidates for anti-amyloid interventions at the predementia stages of $\mathrm{AD}$. 
The goal of managing any disease is primary prevention and, ultimately, we anticipate blood-based assays of amyloid dysregulation or other changes that will enable primary prevention studies. We can envision eventual management of such indicators of risk of amyloid accumulation with secretase inhibitors, other drug therapies, and lifestyle management to minimize reversible contributors to disease.

\section{Conclusions/discussion}

While we have traditionally described $\mathrm{AD}$ in terms of clinically apparent stages, we now have enough understanding of the disease course from pathophysiological, biomarker, and clinical perspectives to appreciate the need to consider $\mathrm{AD}$ as a continuum. That is, a process in which pathophysiological changes accumulate and eventually culminate in clinically apparent disease, which then progresses with gradual worsening of cognitive and functional abilities; there are no firm boundaries between the various clinical stages. Based on what we know today, we have endeavored to describe important characteristics along the $\mathrm{AD}$ continuum from disease inception to advanced clinical disease. As noted throughout, there is considerable individual variation along the continuum.

As efforts to detect disease earlier in the continuum and to assess disease more accurately continue, use of biomarkers is becoming a central facet of accurate diagnosis, and the presence or absence of the disease may be determined using biomarkers of AD pathology. While routine biomarker assessment of asymptomatic individuals is not currently justified, use of well-defined biomarkers may provide useful prognostic information in individuals with early subjective cognitive decline, as well as help to establish therapeutic goals of clinical care.

Support for the disease continuum concept is growing, yet how this will be successfully integrated into clinical practice is not yet clear. For example, even with the currently available biomarkers and clinical tools, identifying individuals who will progress along the $\mathrm{AD}$ spectrum, as well as the trajectory of decline, is still fraught with challenges. Indeed, patients and caregivers only raise concerns with their physician when cognitive deficits are obvious, and this likely correlates with later stages of the development of AD neuropathology. In the future, it is hoped that, with better understanding of the AD continuum, earlier detection will lead to both early and accurate diagnosis and intervention. By 2025 it is hoped that effective DMTs will be approved, and biomarker assessment, together with the employment of more sensitive clinical tools, will become the standard of care. Ultimately, it is predicted that we may need to perform a detailed biomarker assessment for individualized risk prediction to ensure treatments reach individuals at the appropriate time to maximize effects.

\section{Abbreviations}

Aß: Amyloid beta; AD: Alzheimer's disease; ADL: Activities of daily living; APOE4: Apolipoprotein protein epsilon 4; APP: Amyloid beta precursor protein; A/T/N: Amyloid, tau, and neurodegeneration; CSF: Cerebrospinal fluid; DMT: Disease-modifying therapy; MCl: Mild cognitive impairment; MMSE: Mini-Mental State Examination; NFT: Neurofibrillary tangle;

PART: Primary age-related tauopathy; PET: Positron emission tomography

\section{Acknowledgements}

Not applicable.

Funding

Not applicable.

\section{Availability of data and materials}

Not applicable.

\section{Authors' contributions}

PSA, JC, BD, LF, CRJ, JCM, RS, RWJ, BRM, JR, and PS conceived the idea. PSA, $J C, B D, L F, C R J, J C M, R S, R W J, S A D, B R M, J R$, and PS provided written input on scientific content of drafts and approved the final draft for submission.

Ethics approval and consent to participate

Not applicable.

\section{Consent for publication}

Not applicable.

\section{Competing interests}

PSA reports being a consultant to NeuroPhage, Merck, Roche, Novartis, Lundbeck, Biogen, Probiodrug, Anavex, and Abbvie; and receiving grants from Eli Lilly and Company, Janssen, the Alzheimer's Association, and the $\mathrm{NIH}$. JC reports providing consultation to Abbvie, Acadia, Actinogen, Alzheon, Anavex, Avanir, Axovant, Biogen-Idec, Boehringer-Ingelhiem, Bracket, Dart, Eisai, Eli Lilly and Company, Genentech, Lundbeck, MedAvante, Merck, Orion, Otsuka, Pfizer, Roche, Suven, and Takeda; and acknowledges the support of Keep Memory Alive and the National Institute of General Medical Sciences (Grant: P20GM109025). BD reports having received consultancy fees from Eli Lilly and Company and Boehringer-Ingelheim; and research funding for his Institution from Roche and Fondation Merck Avenir. LF reports receiving honoraria or consultation fees from Avid-Eli Lilly and Company, Astra-Zeneca, Axon Neuroscience, Baxter, Bayer, BoehringerIngelheim, Eisai, GE Health Care, Janssen-Cilag, Lundbeck, MerckSharpe \& Dohme, Merz Pharma, Novartis, Pfizer, Schering-Plough, Schwabe Pharma, TAD Pharma, and Takeda; and receiving grants from Piramal and Novartis. CRJ reports having provided consulting services for Eli Lilly and Company; owning stock in Johnson and Johnson; and receiving research funding from the National Institutes of Health (R01-AG011378, RO1-AG041851, U01AG06786, U01-AG024904, R01-AG37551, R01-AG043392, R01-NS092625) and the Alexander Family Alzheimer's Disease Research Professorship of the Mayo Foundation. RWJ reports honoraria and/or consultation fees from AC Immune, Eli Lilly and Company, Lundbeck, MSD, Novartis, Otsuka, and Roche; and his Institute has received grants for clinical trials from AC Immune, Acadia, Axovant, Biogen, Boehringer-Ingelheim, Eli Lilly and Company, Genentech, MSD, Pfizer, and Roche. JCM reports that neither he nor his family owns stock or has equity interest (outside of mutual funds or other externally directed accounts) in any pharmaceutical or biotechnology company; reports participating in the execution of trials of antidementia drugs from Eli Lilly and Company, Biogen, and Janssen; reports serving as a consultant for Eli Lilly and Company; reports receiving research support from Eli Lilly/Avid Radiopharmaceuticals; and reports receiving funding by $\mathrm{NIH}$ grants (P50AG005681; P01AG003991; P01AG026276, and UF01AG032438). RS reports receiving research funding from the National Institute on Aging, the Alzheimer's Association, Fidelity Biosciences, and several philanthropic organizations, Eli Lilly and Co., and Janssen Pharmaceuticals; and has served as a paid consultant to Abbvie, Biogen, Bracket, Eisai, Genentech, Lundbeck, Merck, Otsuka, Roche, and Sanofi. SAD, BRM, and JR report being full-time employees and minor stockholders of Eli Lilly and Company. PS reports having acquired grant support from GE Healthcare, Danone Research, Piramal, and MERCK; having received in the past 2 years consultancy/speaker fees (paid to the institution) from Eli Lilly and Company, GE Healthcare, 
Novartis, Sanofi, Nutricia, Probiodrug, Biogen, Roche, Avraham, and EIP Pharma; and is editor-in-chief of Alzheimer's Research \& Therapy, but had no role in any part of the editorial process of this manuscript.

\section{Publisher's Note}

Springer Nature remains neutral with regard to jurisdictional claims in published maps and institutional affiliations.

\section{Author details}

${ }^{1}$ University of Southern California, San Diego, CA, USA. ${ }^{2}$ Cleveland Clinic Lou Ruvo Center for Brain Health, Las Vegas, NV, USA. ${ }^{3}$ Department of Geriatric Psychiatry, Central Institute of Mental Health, Medical Faculty Mannheim, University of Heidelberg, Mannheim, Germany. ${ }^{4}$ Department of Radiology, Mayo Clinic, Rochester, MN, USA. ${ }^{5}$ The Research Institute for the Care of Older People (RICE), Royal United Hospital, Bath, UK. ${ }^{6}$ Knight Alzheimer Disease Research Center, Washington University School of Medicine, St Louis, MO, USA. ${ }^{7}$ Center for Alzheimer's Research and Treatment, Brigham and Women's Hospital, Harvard Medical School, Boston, MA, USA. ${ }^{8}$ Eli Lilly and Company, Indianapolis, IN, USA. ${ }^{9}$ Eli Lilly Canada Inc., Toronto, ON, Canada. ${ }^{10}$ Department of Neurology \& Alzheimer Center, VU University Medical Center, Amsterdam, The Netherlands. ${ }^{11}$ Institute for Memory and Alzheimer's Disease (IM2A) and ICM, Salpêtrière University Hospital, Paris University (UPMC), Paris, France.

Received: 25 April 2017 Accepted: 4 July 2017

Published online: 09 August 2017

\section{References}

1. Essay HJ. A hundred years of Alzheimer's disease research. Neuron. 2006;52: 3-13.

2. Glenner GG, Wong CW, Quaranta V, Eanes ED. The amyloid deposits in Alzheimer's disease: their nature and pathogenesis. Appl Pathol. 1984;2:357-69.

3. Brion JP, Passareiro H, Nunez J, Flament-Durand J. Mise en evidence de la immunologique de la protein tau au lesions de degeneresescence neurofibrillaire de la maladie. Arch Biol (Brux). 1985;95:229-35.

4. Cummings J, Aisen PS, DuBois B, Frölich L, Jack Jr CR, Jones RW, et al. Drug development in Alzheimer's disease: the path to 2025. Alzheimers Res Ther. 2016. vol. 8. doi:10.1186/s13195-016-0207-9.

5. Hardy DJ, Selkoe J. The amyloid hypothesis of Alzheimer's disease: progress and problems on the road to therapeutics. Science. 2002;297:353-6.

6. Price JL, McKeel Jr DW, Buckles VD, Roe CM, Xiong C, Grundman M, et al. Neuropathology of nondemented aging: presumptive evidence for preclinical Alzheimer disease. Neurobiol Aging. 2009;30:1026-36.

7. Vos SJ, Xiong C, Visser PJ, Jasielec MS, Hassenstab J, Grant EA, et al. Preclinical Alzheimer's disease and its outcome: a longitudinal cohort study. Lancet Neurol. 2013;12:957-65. doi:10.1016/S1474-4422(13)70194-7.

8. Braak H, Braak E. Neuropathological stageing of Alzheimer-related changes. Acta Neuropathol. 1991;82:239-59.

9. Gomez-Isla T, Hollister R, West H, Mui S, Growdon JH, Petersen RC, Parisi JE, Hyman BT. Neuronal loss correlates with but exceeds neurofibrillary tangles in Alzheimer's disease. Ann Neurol. 1997;41:17-24.

10. De Strooper B, Karran E. The cellular phase of Alzheimer's disease. Cell. 2016 164:603-15.

11. Raskin J, Cummings J, Hardy J, Schuh K, Dean RA. Neurobiology of Alzheimer's disease: integrated molecular, physiological, anatomical, biomarker, and cognitive dimensions. Curr Alzheimer Res. 2015;12:712-22.

12. Ittner LM, Götz J. Amyloid- $\beta$ and tau - a toxic pas de deux in Alzheimer's disease. Nat Rev Neurosci. 2011:12:65-72.

13. Arendt T, Stieler JT, Holzer M. Tau and tauopathies. Brain Res Bull. 2016;126: 238-92.

14. Crary JF, Trojanowski JQ, Schneider JA, et al. Primary age-related tauopathy (PART): a common pathology associated with human aging. Acta Neuropathol. 2014;128:755-66.

15. Jellinger KA, Alafuzoff I, Attems J, Beach TG, Cairns NJ, Crary JF, et al. PART, a distinct tauopathy, different from classical sporadic Alzheimer disease. Acta Neuropathol. 2015;129:757-62.

16. Sperling RA, Aisen P, Beckett L, Bennett DA, Craft S, Fagan AM, et al. Towards defining the preclinical stage of Alzheimer's disease: recommendations from the National Institute on Aging and the Alzheimer's Association workgroup. Alzheimers Dement. 2011;7:280-92.
17. Mormino EC, Betensky RA, Hedden T, Schultz AP, Ward A, Huijbers W, et al. Amyloid and APOE \&4 interact to influence short-term decline in preclinical Alzheimer disease. Neurology. 2014;82:1760-7. doi:10.1212/WNL 0000000000000431

18. Stern Y. Cognitive reserve in ageing and Alzheimer's disease. Lancet Neurol. 2012;11:1006-12.

19. Ngandu T, Lehtisalo J, Solomon A, Levälahti E, Ahtiluoto S, Prof Antikainen $\mathrm{R}$, et al. A 2 year multidomain intervention of diet, exercise, cognitive training, and vascular risk monitoring versus control to prevent cognitive decline in at-risk elderly people (FINGER): a randomised controlled trial. Lancet. 2015;385:2255-63. doi:10.1016/S0140-6736(15)60461-5.

20. Rusanen M, Kivipelto M, Quesenberry Jr CP, Zhou J, Whitmer RA. Heavy smoking in midlife and long-term risk of Alzheimer disease and vascular dementia. Arch Intern Med. 2011;171:333-9.

21. Solomon A, Mangialasche F, Richard E, Andrieu S, Bennett DA, Breteler M, et al. Advances in the prevention of Alzheimer's disease and dementia. J Intern Med. 2014:275:229-50. doi:10.1111/joim.1217.

22. PREVENT Dementia. http://preventdementia.co.uk/. Accessed 10 March 2017

23. Dubois B, Feldman HH, Jacova C, Hampel H, Molinuevo JL, Blennow K Dubois B, Feldman HH, Jacova C, Hampel H, Molinuevo J, Dubois B, Feldman $\mathrm{HH}$, Jacova $\mathrm{C}$, Hampel $\mathrm{H}$, Molinuevo J, Blennow K, et al. Advancing research diagnostic criteria for Alzheimer's disease: the IWG-2 criteria. Lancet Neurol. 2014;13:614-29. Erratum in: Lancet Neurol. 2014;13:757.

24. Jack Jr CR, Wiste HJ, Vemuri P, Weigand SD, Senjem ML, Zeng G, et al. Alzheimer's Disease Neuroimaging Initiative. Brain beta-amyloid measures and magnetic resonance imaging atrophy both predict time-to-progression from mild cognitive impairment to Alzheimer's disease. Brain. 2010;133: 3336-48.

25. Jack Jr CR, Knopman DS, Jagust WJ, Petersen RC, Weiner MW, Aisen PS, et al. Tracking pathophysiological processes in Alzheimer's disease: an updated hypothetical model of dynamic biomarkers. Lancet Neurol. 2013;12:207-16

26. Bateman RJ, Xiong C, Benzinger TL, Fagan AM, Goate A, Fox NC, et al. Dominantly Inherited Alzheimer Network. Clinical and biomarker changes in dominantly inherited Alzheimer's disease. N Engl J Med. 2012;367:795-804.

27. Benzinger TL, Blazey T, Jack Jr CR, Koeppe RA, Su Y, Xiong C, et al. Regional variability of imaging biomarkers in autosomal dominant Alzheimer's disease. Proc Natl Acad Sci U S A. 2013;110:E4502-9. doi:10.1073/pnas.

28. Fleisher AS, Chen K, Quiroz YT, Jakimovich L, Gutierrez Gomez M, Langois CM, et al. Associations between biomarkers and age in the presenilin 1 E280A autosomal dominant Alzheimer disease kindred: a cross-sectional study. JAMA Neurol. 2015;72:316-24. doi:10.1001/jamaneurol.2014.3314.

29. van Rossum IA, Visser PJ, Knol DL, van der Flier WM, Teunissen CE, Barkhof $F$, et al. Injury markers but not amyloid markers are associated with rapid progression from mild cognitive impairment to dementia in Alzheimer's disease. J Alzheimers Dis. 2012:29:319-27.

30. Ossenkoppele R, Schonhaut DR, Schöll M, Lockhart SN, Ayakta N, Baker SL, et al. Tau PET patterns mirror clinical and neuroanatomical variability in Alzheimer's disease. Brain. 2016;139:1551-67.

31. Villemagne $V L$, Burnham $S$, Bourgeat $P$, Brown B, Ellis KA, Salvado $O$, et al. Amyloid $\beta$ deposition, neurodegeneration, and cognitive decline in sporadic Alzheimer's disease: a prospective cohort study. Lancet Neurol. 2013;12:357-67. doi:10.1016/S1474-4422(13)70044-9.

32. Ossenkoppele R, Cohn-Sheehy BI, La Joie R, Vogel JW, Möller C, Lehmann $M$, et al. Atrophy patterns in early clinical stages across distinct phenotypes of Alzheimer's disease. Hum Brain Mapp. 2015;36:4421-37.

33. Jansen WJ, Ossenkoppele R, Knol DL, Tijms BM, Scheltens P, Verhey FR, et al. Prevalence of cerebral amyloid pathology in persons without dementia: a meta-analysis. JAMA. 2015;313:1924-38. doi:10.1001/jama.2015.4668.

34. Corder EH, Saunders AM, Strittmatter WJ, Schmechel DE, Gaskell PC, Small GW, et al. Gene dose of apolipoprotein E type 4 allele and the risk of Alzheimer's disease in late onset families. Science. 1993;261:921-3.

35. Chartier-Harlin MC, Parfitt M, Legrain S, Pérez-Tur J, Brousseau T, Evans A, et al. Apolipoprotein E, epsilon 4 allele as a major risk factor for sporadic early and late-onset forms of Alzheimer's disease: analysis of the 19q13.2 chromosomal region. Hum Mol Genet. 1994;3:569-74.

36. Petersen RC, Wiste HJ, Weigand SD, Rocca WA, Roberts RO, Mielke MM, et al. Association of elevated amyloid levels with cognition and biomarkers in cognitively normal people from the community. JAMA Neurol. 2016;73: 85-92. Erratum in: JAMA Neurol. 2016;73:481. 
37. Johnson DK, Storandt M, Morris JC, Galvin JE. Longitudinal study of the transition from healthy aging to Alzheimer disease. Arch Neurol. 2009;66: 1254-9.

38. Donohue MC, Sperling RA, Salmon DP, Rentz DM, Raman R, Thomas RG, et al. The preclinical Alzheimer cognitive composite: measuring amyloidrelated decline. JAMA Neurol. 2014;71:961-70.

39. Jessen F. Subjective and objective cognitive decline at the pre-dementia stage of Alzheimer's disease. Eur Arch Psychiatry Clin Neurosci. 2014;264:S3-7.

40. Liu-Seifert H, Siemers E, Price K, Han B, Selzler KJ, Henley D, et al. Cognitive impairment precedes and predicts functional impairment in mild Alzheimer's disease. J Alzheimers Dis. 2015;47:205-14.

41. Dubois B, Feldman HH, Jacova C, Dekosky ST, Barberger-Gateau P, Cummings J, et al. Research criteria for the diagnosis of Alzheimer's disease: revising the NINCDS-ADRDA criteria. Lancet Neurol. 2007;6:734-46.

42. Albert MS, DeKosky ST, Dickson D, Dubois B, Feldman HH, Fox NC, et al. The diagnosis of mild cognitive impairment due to Alzheimer's disease: recommendations from the National Institute on Aging-Alzheimer's Association workgroups on diagnostic guidelines for Alzheimer's disease. Alzheimers Dement. 2011;7:270-9.

43. McKhann GM, Knopman DS, Chertkow H, Hyman BT, Jack CR, Kawash CH, et al. The diagnosis of dementia due to Alzheimer's disease: Recommendations from the National Institute on Aging and the Alzheimer's Association workgroup. Synergistic effect of $\beta$-amyloid and neurodegeneration on cognitive decline in clinically normal individuals. JAMA Neurol. 2014;71:1379-85.

44. Wagner M, Wolf S, Reischies FM, Daerr M, Wolfsgruber S, Jessen F, et al. Biomarker validation of a cued recall memory deficit in prodromal Alzheimer disease. Neurology. 2012;78:379-86.

45. Jekel K, Damian M, Wattmo C, Hausner L, Bullock R, Connelly PJ, et al. Mild cognitive impairment and deficits in instrumental activities of daily living: a systematic review. Alzheimers Res Ther. 2015;7:17.

46. Jack Jr CR, Bennett DA, Blennow K, Carrillo MC, Feldman HH, Frisoni GB, et al. A/T/N: An unbiased descriptive classification scheme for Alzheimer disease biomarkers. Neurology. 2016;87:539-47.

47. Dubois B, Hampel H, Feldman HH, Scheltens P, Aisen P, Andrieu S, Bakardjian $\mathrm{H}$, et al. Proceedings of the Meeting of the International Working Group (IWG) and the American Alzheimer's Association on "The Preclinical State of AD"; July 23, 2015; Washington DC, USA. Alzheimers Dement. 2016; 12:292-323.

48. Arnerić SP, Batrla-Utermann R, Beckett L, Bittner T, Blennow K, Carter L, et al. Cerebrospinal fluid biomarkers for Alzheimer's disease: a view of the regulatory science qualification landscape from the Coalition Against Major Diseases CSF Biomarker Team. J Alzheimers Dis. 2017;55:19-35.

49. Chételat $G$, La Joie R, Villain N, Perrotin A, de La Sayette V, Eustache F, Vandenberghe R. Amyloid imaging in cognitively normal individuals, at-risk populations and preclinical Alzheimer's disease. Neuroimage Clin. 2013:2:356-65. doi:10.1016/j.nicl.2013.02.006.

50. Johnson KA, Schultz A, Betensky RA, Becker JA, Sepulcre J, Rentz D, et al. Tau positron emission tomographic imaging in aging and early Alzheimer disease. Ann Neurol. 2016;79:110-9.

51. Siemers E, Sundell K, Carlson C, Case M, Sethuraman G, Liu-Seifert H, et al, Phase 3 solanezumab trials: secondary outcomes in mild Alzheimer's disease patients. Alzheimers Dement. 2016:12:110-20.

52. Petersen RC, Aisen P, Boeve BF, Geda YE, Ivnik RJ, Knopman DS, et al. Mild cognitive impairment due to Alzheimer disease in the community. Ann Neurol. 2013;74:199-208

53. Galasko D, Bennett D, Sano M, Ernesto C, Thomas R, Grundman M, et al. An inventory to assess activities of daily living for clinical trials in Alzheimer's disease. The Alzheimer's disease Cooperative Study. Alzheimer's Disease and Associated Disorders. 1997;11:S33-9.

54. Hamel R, Köhler S, Sistermans N, Koene T, Pijnenburg Y, van der Flier W, et al. The trajectory of cognitive decline in the pre-dementia phase in memory clinic visitors: findings from the 4C-MCI study. Psychol Med. 2015;45:1509-19.

55. Walsh SP. Raman R, Jones KB, Aisen PS, Alzheimer's Disease Cooperative Study Group. ADCS Prevention Instrument Project: the Mail-In Cognitive Function Screening Instrument (MCFSI). Alzheimer Dis Assoc Disord. 2006; 20:5170-8.

56. Marson DC, Sawrie SM, Snyder S, Mclnturff B, Stalvey T, Boothe A, et al. Assessing financial capacity in patients with Alzheimer disease: a conceptual model and prototype instrument. Arch Neurol. 2000:57:877-84.
57. Buschke H, Kuslansky G, Katz M, Stewart WF, Sliwinski MJ, Eckholdt HM, Lipton RB Screening for dementia with the Memory Impairment Screen H. Neurology. 1999;52:231-8. doi:10.1212/WNL.52.2.231.

58. Grober $\mathrm{E}$, Buschke H. Genuine memory deficits in dementia. Dev Neuropsychol. 1987;3:13-36.

59. Galvin JE, Roe CM, Powlishta KK, Coats MA, Muich SJ, Grant E, Miller JP, Storandt M, Morris JC. The AD8: a brief informant interview to detect dementia. Neurology. 2005;65:559-64.

60. Wang J, Logovinsky V, Hendrix S, Stanworth S, Perdoma C, Xu L, et al. ADCOMS: a composite clinical outcome for prodromal Alzheimer's disease trials. J Neurol Neurosurg Psychiatry. 2016;87:993-9. doi:10.1136/jnnp-2015312383

61. Brodaty H, Pond D, Kemp NM, Luscombe G, Harding L, Berman K, Huppert FA. The GPCOG: a new screening test for dementia designed for general practice. J Am Geriatr Soc. 2002:50:530-4.

62. Borson S, Scanlan J, Brush M, Vitaliano P, Dokmak A. The mini-cog: a cognitive "vital signs" measure for dementia screening in multi-lingual elderly. Int J Geriatr Psychiatry. 2000;15:1021-7.

63. Randolph C, Tierney MC, Mohr E, Chase TN. The Repeatable Battery for the Assessment of Neuropsychological Status (RBANS): preliminary clinical validity. J Clin Exp Neuropsych. 1988;20:310-9.

64. Dubois B, Touchon J, Portet F, Ousset PJ, Vellas B, Michel B. The "5-words": a simple and sensitive test for the diagnosis of Alzheimer's disease. Presse Med. 2002;31:1696-9.

65. Mormont $E$, Jamart J. Robaye $L$ Validity of the five-word test for the evaluation of verbal episodic memory and dementia in a memory clinic setting. J Geriatr Psychiatry Neurol. 2012;25:78-84.

66. Elwood RW. The California Verbal Learning Test: psychometric characteristics and clinical application. Neuropsychol Rev. 1995;5:173-201.

67. Nasreddine ZS, Phillips NA, Bédirian V, Charbonneau S, Whitehead V, Collin I, Cummings JL, Chertkow $\mathrm{H}$. The Montreal Cognitive Assessment, MoCA: a brief screening tool for mild cognitive impairment. J Am Geriatr Soc. 2005; 53:695-9.

68. Noone P. Addenbrooke's Cognitive Examination-III. Occup Med (Lond). 2015;65:418-20. doi:10.1093/occmed/kqv041.

69. Folstein MF, Folstein SE, McHugh PR. "Mini-mental state": a practical method for grading the cognitive state of patients for the clinician. J Psychiatr Res. 1975;12:189-98

70. Rosen WG, Mohs RC, Davis KL. A new rating scale for Alzheimer's disease. Am J Psychiatry. 1984;41:1356-64.

71. Berg L. Clinical Dementia Rating (CDR). Psychopharm Bull. 1988;24:637-9.

72. Saxton J, Swihart AA. Neuropsychological assessment of the severely impaired elderly patient. Clin Geriatr Med. 1989;5:531-43. 